\title{
Dexamethasone protects normal human liver cells from apoptosis induced by tumor necrosis factor-related apoptosis-inducing ligand by upregulating the expression of P-glycoproteins
}

\author{
BO ZHAO, GUI-JUAN XIE, RUI-FENG LI, QING CHEN and XU-QING ZHANG \\ Department of Infectious Diseases, Southwest Hospital, Third Military Medical University, Chongqing 400038, P.R. China
}

Received December 17, 2014; Accepted September 9, 2015

DOI: $10.3892 / \mathrm{mmr} .2015 .4458$

\begin{abstract}
Glucocorticoids are effective for the treatment of acute-on-chronic pre-liver failure, severe chronic hepatitis B and acute liver failure; however, the mechanism underlying the effects of treatment by glucocorticoids remains to be fully elucidated. The role and detailed mechanism of how glucocorticoids prevent liver disease progression can be elucidated by investigating the apoptosis of hepatocytes following glucocorticoid treatment. P-glycoproteins (P-gps) also confer resistance to apoptosis induced by a diverse range of stimuli. Glucocorticoids, particularly dexamethasone (DEX), upregulate the expression of P-gp in several tissues. In the present study, the normal human L-02 liver cell line was used, and techniques, including immunocytochemistry, western blot analysis, flow cytometry and reverse transcription-quantitative polymerase chain reaction analysis were used for determining the expression levels of P-gps, and for evaluating the effect of DEX pretreatment on the expression of P-gps. DEX $(1-10 \mu \mathrm{M})$ was added to the cell culture media and incubated for 24-72 h. The results revealed that DEX upregulated the mRNA and protein levels of P-gp in a dose- and time-dependent manner. Subsequently, tumor necrosis factor-related apoptosis-inducing ligand (TRAIL) was used for the induction of apoptosis in the cells, followed by a terminal deoxynucleotidyl transferase dUTP nick end labeling assay to assess the apoptotic stages. The results demonstrated that apoptosis in the group of cells,
\end{abstract}

Correspondence to: Professor Xu-Qing Zhang, Department of Infectious Diseases, Southwest Hospital, Third Military Medical University, 30 Gaotanyan Street, Shapingba, Chongqing 400038, P.R. China

E-mail: xuqing651005@tom.com

Abbreviations: DEX, dexamethasone; P-gp, P-glycoprotein; TRAIL, tumor necrosis factor-related apoptosis-inducing ligand; TUNEL, terminal deoxynucleotidyl transferase dUTP nick end labeling; pre-ACLF, acute-on-chronic pre-liver failure; ACLF, acute-on-chronic liver failure; NA, nucleoside analog; MDR, multidrug resistance; PXR, pregnane $\mathrm{X}$ receptor; TQD, tariquidar

Key words: multidrug resistance protein, P-glycoprotein, dexamethasone, L-02 cell, apoptosis which were pre-treated with DEX was significantly lower than that in the control group. Treatment with tariquidar, a P-gp inhibitor, reduced the anti-apoptotic effects of DEX. These results established that DEX protects normal human liver cells from TRAIL-induced apoptosis by upregulating the expression of P-gp. These observations may be useful for elucidating the mechanism of DEX for preventing the progression of liver disease.

\section{Introduction}

Patients with severe acute exacerbation of chronic hepatitis $\mathrm{B}$ virus (HBV) infection, including acute-on-chronic pre-liver failure (pre-ACLF), are at risk for potential progression to acute-on-chronic liver failure (ACLF) with high rates of mortality $(1,2)$. Therefore, it is important to investigate therapies, which can prevent the progression of severe acute episodes to liver failure in patients with chronic HBV. The role of antiviral treatments, including nucleoside analogs in preventing the progression of severe HBV to liver failure remains to be elucidated. However, glucocorticoids are effective for the treatment of pre-ACLF, severe and potentially life-threatening exacerbation of chronic HBV and acute liver failure $(3,4)$. Studies have indicated that the mechanisms by which glucocorticoids prevent the progression of liver disease include: (i) Prevention of HBV-induced primary liver injuries by inhibiting excessive immune responses; (ii) prevention of endotoxin-induced secondary liver injuries by inhibiting the production of oxygen-free radicals and cytokines (5); (iii) prevention of cytolysis of ballooned hepatocytes by stabilizing the lysosomal membrane, and inhibiting the production of lysosomal proteases and circulating toxic substances (6); and (iv) improvement in the functional activity of the residual hepatocytes (7). However, the mechanisms by which glucocorticoid treatment alleviates various liver conditions remain to be fully elucidated. Similar to hepatic necrosis, apoptosis of hepatocytes is also a key feature of almost all acute and chronic cases of HBV, including acute liver failure (8). Therefore, investigating the role of glucocorticoids and their underlying mechanism in preventing the apoptosis of hepatocytes is necessary for improved treatment of severe chronic HBV and acute liver failure associated with HBV infection. Dexamethasone (DEX) is a synthetic glucocorticoid, which inhibits apoptosis in certain cells, including human neutrophils, hair cells, human 
fibroblasts and primary rat hepatocytes; and induces apoptosis in other cells, including thymocytes and lymphocytes $(9,10)$. DEX also enhances trichosanthin-induced apoptosis in the HepG2 hepatoma cell line (11). However, the precise mechanism by which DEX inhibits or induces apoptosis remains to be elucidated.

Multidrug resistant (MDR) P-glycoprotein (P-gp), encoded by the ABCB1 gene, was first discovered in MDR tumor cells, where it reduces the cellular accumulation of chemotherapeutic agents $(12,13)$. In addition to being expressed in cancer cells, P-gps are also expressed in normal tissues, where they have an important protective role in limiting the absorption and/or facilitating the excretion of a wide range of substrates, by actively transporting substrates from the inner to the outer leaflets of the cell membranes (14). In addition to their ability to discharge toxins, P-gps can also inhibit apoptosis, which is induced by a wide array of cell death stimuli that rely on the activation of intracellular caspases for complete functionality (15-17). Therefore, the present study hypothesized that the expression of P-gps in hepatocytes also have an important hepatoprotective role. A number of studies have reported that glucocorticoids, particularly DEX, are able to improve the blood-brain barrier and placental barrier functions by increasing the expression and function of P-gps $(18,19)$. DEX increases the expression of pregnane $X$ receptor $(\mathrm{PXR})$ at the transcriptional level, and PXR mediates the spironolactone-induced expression of P-gp in HepG2 cells (20).

Based on evidence that DEX and P-gps have the ability to prevent the apoptosis induced by a wide array of cell death stimuli, and that DEX alone induces the expression and function of P-gps in several organs and cells; the present study hypothesized that DEX prevents apoptosis in human hepatocytes by upregulating the expression of P-gp. At present, few studies detailing the role of P-gps in the inhibition of hepatocyte apoptosis by DEX have been performed. The present study was performed to determine the anti-apoptotic effects of DEX on the L-02 normal human liver cell line, and to ascertain whether the anti-apoptotic effects are associated with an upregulation in the expression of P-gp. The results from these investigation aim to establish whether DEX protects L-02 normal human liver cells from tumor necrosis factor-related apoptosis-inducing ligand (TRAIL)-induced apoptosis, by upregulating the expression of P-gps.

\section{Materials and methods}

Materials. The L-02 normal human liver cell line was purchased from the Shanghai Institute of Biochemistry and Cell Biology, Chinese Academy of Sciences (Shanghai, China). RPMI 1640 medium was purchased from Gibco Life Technologies (Carlsbad, CA, USA) and newborn bovine serum was purchased from Lanzhou Minhai Bioengineering Co. Ltd. (Lanzhou, China). Trypsin $(0.25 \%)$ was purchased from GE Healthcare Life Sciences (Logan, UT, USA) and DEX was purchased from Chongqing Xi'nan Pharmaceutical Group Co., Ltd. (Chongqing, China). Primary mouse anti-human monoclonal P-gp antibody (cat. no. ab3366) was obtained from Abcam (Cambridge, UK). An avidin-free, polymer detection kit [PV-9000; containing a polymer helper (reagent 1) and polyperoxidase anti-mouse/rabbit IgG (reagent 2)] for immunocytochemical staining and hematoxylin were purchased from Zhongshan Golden Bridge Biotechnology Co., Ltd., (Beijing, China). Hydrogen peroxide was purchased from Chongqing Chuandong Chemical Group Co., Ltd. (Chongqing, China) IC fixation buffer (cat. no. 00-8222) and permeabilization buffer (cat. no. 00-8333) were purchased from eBioscience, Inc. (San Diego, CA, USA). Fluorescein isothiocyanate (FITC)-conjugated goat anti-mouse secondary antibody was purchased from Zhongshang Golden Bridge Biotechnology Co., Ltd. (cat. no. ZF-0312). Radioimmunoprecipitation assay (RIPA) cell lysis buffer, the bicinchoninic acid (BCA) protein assay kit and horseradish peroxidase-labeled goat anti-mouse secondary antibody (cat. no. A0216) were purchased from Beyotime Institute of Biotechnology (Jiangshu, China). Polyvinylidene fluoride (PVDF) membranes were purchased from EMD Millipore (Billerica, MA,USA). SDS was purchased from Sigma-Aldrich (St. Louis, MO, USA), and acrylamide was purchased from Bio-Rad Laboratories Inc. (Hercules, CA, USA). The UNIQ-10 TRIzol total RNA extraction kit and paraformaldehyde were obtained from Sangon Biotech Co., Ltd. (Shanghai, China). The QuantScript reverse transcription kit was obtained from Tiangen Biotech Co., Ltd. (Beijing, China). The Mx3000P Real-Time QPCR System was obtained from Agilent Technologies, Inc. (Santa Clara, CA, USA). The FastStart Universal SYBR Green Master kit was obtained from Roche Diagnostics (Basel, Switzerland). The primers for the ABCB1 gene, encoding P-gp, were synthesized according to the method reported by Jigore et al (21). The primers for the $\beta$-actin gene were synthesized by Sangon Biotech. All the primers used for the reverse transcription-quantitative polymerase chain reaction (RT-qPCR) analysis were purchased from Sangon Biotech Co., Ltd. The sequences of the primer pairs were as follows: ABCB1, forward, 5'-GCCAAAGCCAAAATATCAGC-3' and reverse, 5'-TTCCAATGTGTTCGGCATTA-3'; and $\beta$-actin, forward 5'-GACGACATGGAGAAAA-3' and reverse 5'-AAGGCTGGA AGAGTGC-3'. Recombinant Human sTRAIL/Apo2 L (TRAIL) was obtained from PeproTech, Inc. (Rocky Hill, NJ, USA). The in situ Cell Death Detection kit, POD, was purchased from Roche Diagnostics and tariquidar (TQD) was purchased from Selleck Chemicals (Shanghai, China).

Human L-02 cellculture and induction with DEX. The L-02 cells were seeded in 6 -well plates or $75-\mathrm{cm}^{2}$ culture flasks (Nunc, Roskilde, Denmark) at a density of $5 \times 10^{5}$ cells/ml, and cultured in RPMI 1640 medium supplemented with $10 \%(\mathrm{v} / \mathrm{v})$ newborn bovine serum at $37^{\circ} \mathrm{C}$ and $5 \% \mathrm{CO}_{2}$. Following treatment with varying concentrations (1 and $10 \mu \mathrm{M})$ of DEX at $37^{\circ} \mathrm{C}$ for $24-72 \mathrm{~h}$, the cells were harvested for detection of the expression of P-gp. Untreated cells were used as a control group.

Immunocytochemistry. Following fixation with $4 \%$ paraformaldehyde for $10 \mathrm{~min}$, the cells were processed for immunocytochemistry by staining using a PV-9000 avidin-free polymer detection system. The procedures included the following steps: i) Incubation with $3 \%$ hydrogen peroxide for $10 \mathrm{~min}$ to inhibit the activity of endogenous peroxidase; ii) incubation with the primary mouse anti-human 
monoclonal P-gp antibody (cat. no. ab3366; 1:50 dilution; Abcam) at $4^{\circ} \mathrm{C}$ overnight, followed by incubation with the polymer helper (reagent 1 ) at $37^{\circ} \mathrm{C}$ for $20 \mathrm{~min}$; iii) incubation with polyperoxidase anti-mouse/rabbit IgG (reagent 2) at $37^{\circ} \mathrm{C}$ for $20 \mathrm{~min}$; iv) development of the peroxidase reaction with 3,3'-Diaminobenzidine (DAB) tetrahydrochloride following three washes with phosphate-buffered saline (PBS); and v) counterstaining of the cells with hematoxylin. In the negative control group, the primary antibody (cat. no. ab3366) was substituted with PBS. The cells were examined and images were captured under an Olympus IX70 microscope (Olympus Corporation, Beijing, China). Image-Pro Plus image analysis software v6.0 (Media Cybernetics, Inc., Rockville, MD, USA) was used for quantitatively assessing the optical densities.

Flow cytometric analysis. Flow cytometry was performed on a BD FACSCalibur flow cytometer (BD Biosciences, San Jose, CA, USA). Briefly, $10^{6}$ cells were trypsinized in each well of a 6-well plate, washed with PBS and resuspended in PBS. The cells were fixed and permeabilized using the IC fixation and permeabilization buffers, respectively, according to the manufacturer's instructions (eBioscience, Inc.). The cells were incubated with primary mouse anti-human monoclonal P-gp antibody (ab3366; 1:50 dilution; Abcam) overnight at $4^{\circ} \mathrm{C}$, followed by incubation with the FITC-conjugated goat anti-mouse secondary antibody (1:50 dilution; cat. no. ZF-0312; Zhongshan Golden Bridge Biotechnology Co., Ltd.) for $20 \mathrm{~min}$ in the dark. Following three washes, the samples were analyzed using the flow cytometer and FlowJo software (v 6.4.7; Tree Star, Inc. Ashland, OR, USA).

Protein extraction and western blot analysis. Total protein was extracted from the cells using RIPA cell lysis buffer, containing $20 \mathrm{mM}$ Tris ( $\mathrm{pH} 7.5), 150 \mathrm{mM} \mathrm{NaCl}$, $1 \%$ Triton $\mathrm{X}-100,2.5 \mathrm{mM}$ sodium pyrophosphate, $1 \mathrm{mM}$ EDTA, $1 \% \mathrm{Na}_{3} \mathrm{VO}_{4}$ and $0.5 \mathrm{mg} / \mathrm{ml}$ leupeptin. A BCA protein assay kit was used for measuring the protein concentrations in the cell extracts. Subsequently, the proteins $(20 \mu \mathrm{g})$ were separated by sodium dodecyl sulfate-polyacrylamide gel electrophoresis on $6 \%$ gels, and were then transferred onto PVDF membranes by electroelution. The membranes were incubated overnight with the primary mouse anti-human monoclonal P-gp antibody (ab3366; 1:50 dilution; Abcam), followed by incubation with the horseradish peroxidase-labeled goat anti-mouse secondary antibody (cat. no. A0216; 1:1,000 dilution; Beyotime Institute of Biotechnology) for $2 \mathrm{~h}$ at room temperature. The bands were visualized using enhanced chemiluminescence (Pierce Biotechnology, Inc., Rockford, IL, USA) and images were captured using a ChemiDoc XRS+ system (Bio-Rad Laboratories, Inc.). The relative intensities in each band were quantified densitometrically using Quantity One Software (v. 4.4.0.36, Bio-Rad Laboratories, Inc.) and calculated by comparing the band densities with those of the reference protein, $\beta$-actin.

Total RNA purification and RT-qPCR. Total RNA was extracted from the cells using a UNIQ-10 TRIzol total RNA extraction kit, according to the manufacturer's instructions. The extracted RNA samples were reverse transcribed into cDNA using a QuantScript reverse transcription kit. qPCR was performed on an Mx3000P Real-Time QPCR System using the FastStart Universal SYBR Green master kit. qPCR was performed in 96-well plates, with each well containing 1X FastStart universal SYBR Green master mix, 2X each of the forward and reverse primers, ddH2O and template cDNA, in a $20 \mu \mathrm{l}$ total reaction volume. The DNA template $(1 \mu \mathrm{l})$ was pre-incubated at $95^{\circ} \mathrm{C}$ for 2 min prior to the amplification cycle, followed by 40 cycles of denaturation at $95^{\circ} \mathrm{C}$ for $15 \mathrm{sec}$, and annealing and extension at $60^{\circ} \mathrm{C}$ for $40 \mathrm{sec} . \beta$-actin was used as the reference gene. The relative mRNA expression levels were calculated using the $2^{-\Delta \Delta \mathrm{Ct}}$ method (22). All the experiments were performed in triplicate.

Effects of DEX and TQD on apoptosis induced by TRAIL/Apo $2 \mathrm{~L}$. It has been reported that $\mathrm{P}$-gps can protect cells from apoptosis induced by a wide range of drugs $(23,24)$. To examine the effects of DEX on apoptosis induced by TRAIL in the present study, the L-02 cells were treated with $20 \mathrm{ng} / \mathrm{ml}$ TRAIL for $24 \mathrm{~h}$ to induce apoptosis, followed by treatment with either 1 or $10 \mu \mathrm{M}$ DEX for 24 or $48 \mathrm{~h}$. Untreated cells were used as a control group. A TUNEL assay was performed to analyze the induction of apoptosis by TRAIL in the cells.

For investigating the effects of TQD on apoptosis, the L-02 cells were divided into six groups: i) control group comprising untreated L-02 cells; ii) L-02 cells pretreated with $10 \mu \mathrm{M}$ DEX for $24 \mathrm{~h}$, followed by incubation with TRAIL for $24 \mathrm{~h}$; iii) L-02 cells pretreated with $10 \mu \mathrm{M} \mathrm{DEX}$ for $24 \mathrm{~h}$, followed by a $24 \mathrm{~h}$ incubation with TRAIL and TQD (25 nM); iv) L-02 cells pretreated with $10 \mu \mathrm{M}$ DEX for $24 \mathrm{~h}$, followed by a $24 \mathrm{~h}$ incubation with TRAIL and TQD (50 nM); v) L-02 cells pretreated with $10 \mu \mathrm{M}$ DEX for $24 \mathrm{~h}$, followed by a $24 \mathrm{~h}$ incubation with TRAIL and TQD (100 nM); vi) L-02 cells incubated with TRAIL for $24 \mathrm{~h}$. All the groups were incubated at $37^{\circ} \mathrm{C}$, and with the exception of the control, were treated with TRAIL to induce apoptosis. Following the various treatments, all groups reached the same final cell density of $~ 90 \%$ confluence. Apoptosis was evaluated using the TUNEL assay, and the number of apoptotic cells in each group were counted.

The apoptosis status of the L-02 cells was measured using the TUNEL assay, using a POD In Situ Cell Death Detection kit, according to the manufacturer's instructions. Briefly, following treatment with $4 \%$ paraformaldehyde for $1 \mathrm{~h}$ at room temperature and $3 \%$ hydrogen peroxide for $10 \mathrm{~min}$ at room temperature, the cells ( $\sim 90 \%$ confluence) were washed twice in PBS for $5 \mathrm{~min}$. Following incubation with $0.1 \%$ Triton $\mathrm{X}-100$ on ice for $5 \mathrm{~min}$ and two washes with PBS for $5 \mathrm{~min}$, the labeling reactions were performed using $50 \mu \mathrm{l}$ TUNEL reagent for $1 \mathrm{~h}$ at $37^{\circ} \mathrm{C}$ for each group. Following washing with PBS, the cells were incubated with a converter reagent for $30 \mathrm{~min}$ at $37^{\circ} \mathrm{C}$, developed using DAB for $10 \mathrm{~min}$, and then counterstained with hematoxylin. Following dehydration in ethanol and clearing in xylene, the cells were mounted on slides and examined under a light microscope (Olympus IX70; Olympus Corporation). Apoptotic cells were quantified by counting the number of TUNEL-positive cells in ten random microscopic fields (magnification, x200).

Statistical analysis. The data are presented as the mean \pm standard deviation. One-way analysis of variance was used for determining significant differences. All analyses were 

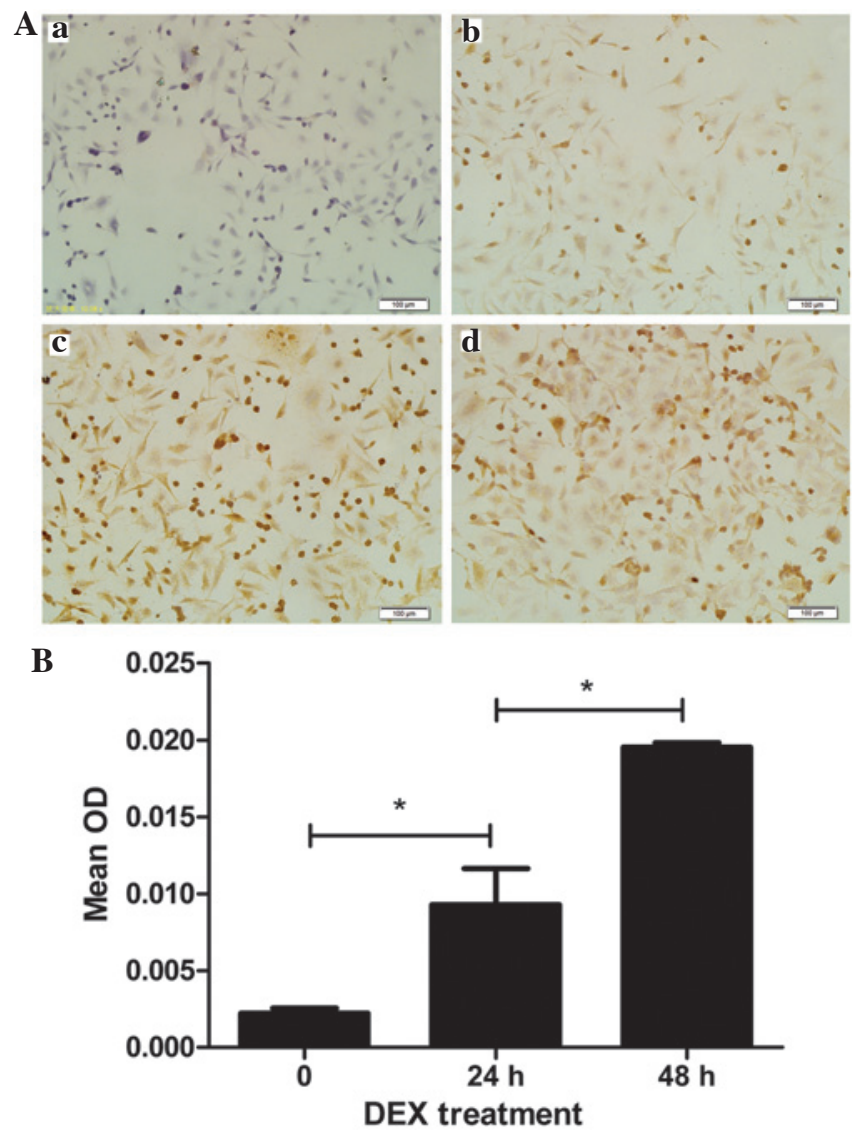

Figure 1. Detection of the expression of P-gp in L-02 cells using immunocytochemistry. (A) Representative immunocytochemical staining of P-gp in the L-02 cells. (a) Negative control; (b) untreated L-02 cells; (c) L-02 cells incubated with $10 \mu \mathrm{M}$ DEX for 24 ; (d) L-02 cells incubated with $10 \mu \mathrm{M}$ DEX for $48 \mathrm{~h}$. The marked positive staining (brown) represents P-gps in the L-02 cells. (B) Quantitative analysis of the immunocytochemical staining. Data are presented as the mean \pm standard deviation. ${ }^{*} \mathrm{P}<0.01$. Magnification, $\mathrm{x} 200$. P-gp. P-gylcoprotein; Dex, dexamethasone; OD, optical density.

performed using the SPSS 13.0 statistical software (SPSS, Inc., Chicago, IL, USA). $\mathrm{P}<0.05$ was considered to indicate a statistically significant difference.

\section{Results}

DEX increases the $m R N A$ and protein expression levels of $P$-gp in the L-O2 cell line. The results from the immunocytochemistry assays demonstrated definitive expression of P-gp in the L-02 normal human liver cell lines, compared with the negative control (Fig. 1Aa and b). Treatment of the L-02 cells with $10 \mu \mathrm{M}$ DEX for 24 and $48 \mathrm{~h}$ resulted in marked P-gp staining in the membrane and in the cytoplasm of the majority of the cells (Fig. 1Ac and d). The protein expression levels of $\mathrm{P}$-gp, presented as mean densitometric units, in the L-02 cells following treatment with $10 \mu \mathrm{M} \mathrm{DEX}$ for 24 and $48 \mathrm{~h}$ were $9.284 \times 10^{-3} \pm 0.578 \times 10^{-2}$ and $19.530 \times 10^{-3} \pm 0.719 \times 10^{-3}$, respectively, which were significantly higher than in the cells without DEX treatment $\left(2.228 \times 10^{-3} \pm 0.770 \times 10^{-3}\right.$; Fig. 1B). The cells, which were incubated for $48 \mathrm{~h}$ with DEX had higher levels of P-gps, compared with those incubated for $24 \mathrm{~h}(\mathrm{P}<0.01)$.

The results of the flow cytometric analysis (Fig. 2) demonstrated that the levels of P-gp were significantly higher in the

L-02 cells treated with $10 \mu \mathrm{M}$ DEX for $48 \mathrm{~h}$, compared with levels in the untreated control group $(\mathrm{P}<0.01)$. Additionally, the levels of P-gp were higher in the cells, which were treated with DEX for $48 \mathrm{~h}$, compared with those treated for $24 \mathrm{~h}$ $(\mathrm{P}=0.014)$. The L-02 cells, which were treated with DEX for $24 \mathrm{~h}$ exhibited a degree of upregulation in the expression of P-gp, compared with the untreated cells; however, no statistical difference was observed between these two groups $(\mathrm{P}=0.054)$.

The protein expression levels of P-gp in the L-02 cells were also determined by western blot analysis, using a monoclonal antibody against P-gp (JSB-1). As shown in Fig. 3, the results revealed a band at $170 \mathrm{kDa}$, which corresponded with P-gp. The results were analyzed quantitatively, according to the grayscale values. The expression of P-gp in the group treated with $1 \mu \mathrm{M}$ DEX for $24 \mathrm{~h}$ were significantly increased, compared with the control group $(\mathrm{P}=0.001)$. Treatment with $10 \mu \mathrm{M}$ DEX for $24 \mathrm{~h}$ resulted in higher expression levels of $\mathrm{P}$-gp than that following $1 \mu \mathrm{M}$ DEX treatment for $48 \mathrm{~h}(\mathrm{P}=0.006)$. In addition, the protein expression levels in the cells treated with $10 \mu \mathrm{M}$ DEX for $72 \mathrm{~h}$ were markedly upregulated, compared with those in the groups treated with $10 \mu \mathrm{M}$ DEX for 24 and $48 \mathrm{~h}(\mathrm{P}<0.05)$. Therefore, it was concluded that the protein expression levels of P-gp increased in a dose-dependent manner, between 1 and $10 \mu \mathrm{M}$ DEX, and a time-dependent manner, between 24 and $72 \mathrm{~h}$ DEX stimulation.

RT-qPCR was used for detecting the mRNA expression levels of the ABCB1 gene, encoding P-gp, in the L-02 cells. As shown in Fig. 4, the present study detected for the first time, to the best of our knowledge, transcription of the ABCB1 gene in the L-02 cell lines. In addition, the effects of DEX on the transcription of ABCB1 mRNA were also demonstrated in the L-02 cell line. The results demonstrated that the mRNA levels of the ABCB1 gene increased in response to treatment with $1 \mu \mathrm{M}$ DEX for $24 \mathrm{~h}$, compared with the control $(\mathrm{P}=0.004)$, similar to the results of the protein levels. During the same time interval, treatment with $1 \mu \mathrm{M}$ and $10 \mu \mathrm{M}$ DEX exhibited differences in mRNA levels, which were significantly higher in the $10 \mu \mathrm{M}$ DEX group, compared with the $1 \mu \mathrm{M}$ group $(\mathrm{P}<0.05)$. Additionally, treatment with DEX for $48 \mathrm{~h}$ lead to increased mRNA levels, compared with treatment with DEX for $24 \mathrm{~h}(\mathrm{P}<0.05)$. These results suggested that treatment with DEX increased the expression of P-gp at the mRNA and protein levels, in a dose- and time-dependent manner.

Effects of DEX on apoptosis induced by TRAIL. As shown in Fig. 5, all the nuclei were stained blue with hematoxylin, whereas the brown color indicated the presence of apoptotic nuclei, which were visualized following staining with DAB reagent. The highest degree of apoptosis was observed in the control group, which was incubated with TRAIL in the absence of DEX. By contrast, treatment with $10 \mu \mathrm{M}$ DEX for $48 \mathrm{~h}$ resulted in the lowest observed levels of apoptosis in the L-02 cells. In addition, the results demonstrated that the degree of DNA fragmentation decreased with prolonged exposure to DEX, between 24-48 h, and increased concentrations of DEX between 1 and $10 \mu \mathrm{M}(\mathrm{P}<0.05)$.

Effects of TQD on apoptosis induced by TRAIL. As shown in Fig. 6, the lowest degree of apoptosis was observed in the 

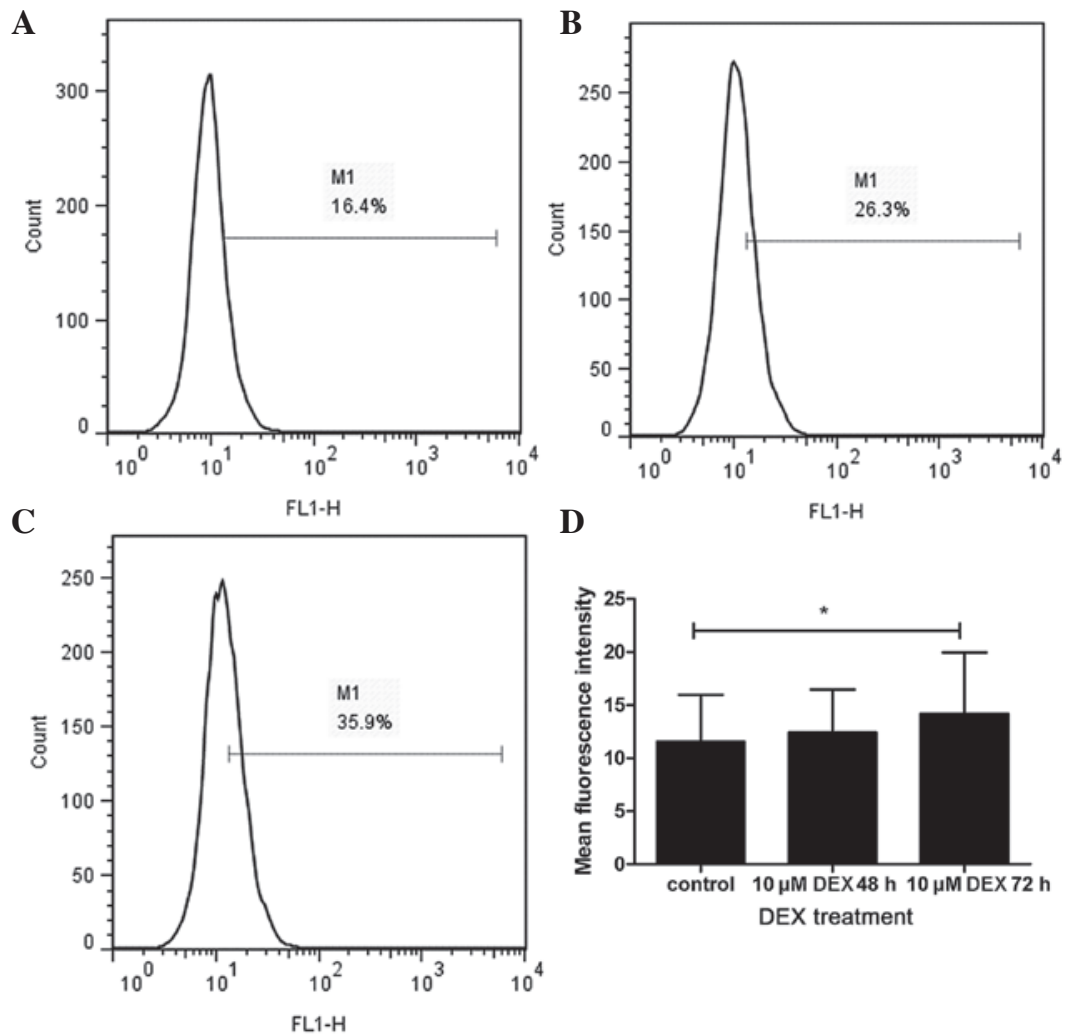

Figure 2. Flow cytometric analysis of the expression of P-gp. The results in each flow cytometry histogram represent one of three independent experiments. (A) Untreated L-02 cells (B) L-02 cells incubated with $10 \mu \mathrm{M}$ DEX for $48 \mathrm{~h}$; (C) L-02 cells incubated with $10 \mu \mathrm{M}$ DEX for $72 \mathrm{~h}$. (D) Quantitative analysis of the flow cytometry data. Data are presented as the mean \pm standard deviation. ${ }^{*} \mathrm{P}<0.01$. P-gp. P-gylcoprotein; DEX, dexamethasone; M1 region, positive cells.

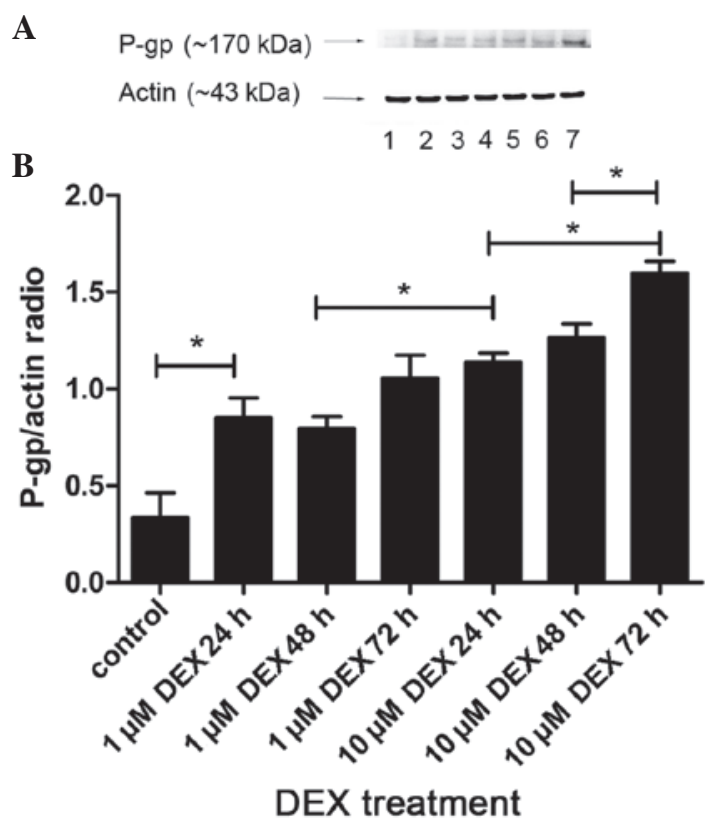

Figure 3. Expression of P-gp, determined using western blot analysis. (A) Representative electrophoretograms of western blots. (1) Untreated L-02 cells, (B) L-02 cells incubated with $1 \mu \mathrm{M}$ DEX for (2) 24 , (3) 48 and (4) $72 \mathrm{~h}$, and with $10 \mu \mathrm{M}$ DEX for (5) 24 , (6) 48 and (7) $72 \mathrm{~h}$. (B) Quantitative analysis of the western blot protein bands. Data are presented as the mean \pm standard deviation. "P<0.05. P-gp. P-gylcoprotein; DEX, dexamethasone.

control group, which comprised L-02 cells cultured in media alone with no additional treatments. These results indicated that the levels of apoptosis in the L-02 cells were intrinsically

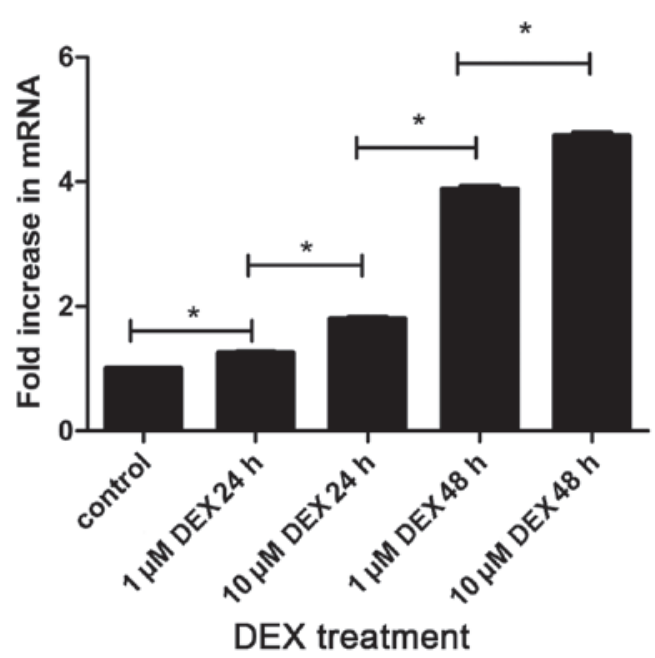

Figure 4. Reverse transcription-quantitative polymerase chain reaction analysis. The L-02 cells were incubated for 24 and $48 \mathrm{~h}$ with 1 or $10 \mu \mathrm{M} \mathrm{DEX}$, with the exception of the control group, which contained only the culture medium. Relative gene expression levels of the ABCB1 gene were analyzed using the $2^{-\Delta \Delta \mathrm{Ct}}$ method. Experiments were performed in triplicate. Data are presented as the mean \pm standard deviation. ${ }^{*} \mathrm{P}<0.05$. DEX, dexamethasone.

low. Following exposure to TRAIL, the levels of apoptosis in the L-02 cells increased markedly. By contrast, pretreatment of the cells with DEX inhibited this apoptosis. Notably, the addition of TQD, which is a P-gp inhibitor, increased the levels of apoptosis. When the concentrations of TQD were increased to 50 and $100 \mathrm{nM}$, statistical significance in the levels of apoptosis were observed, compared with the group treated 
A
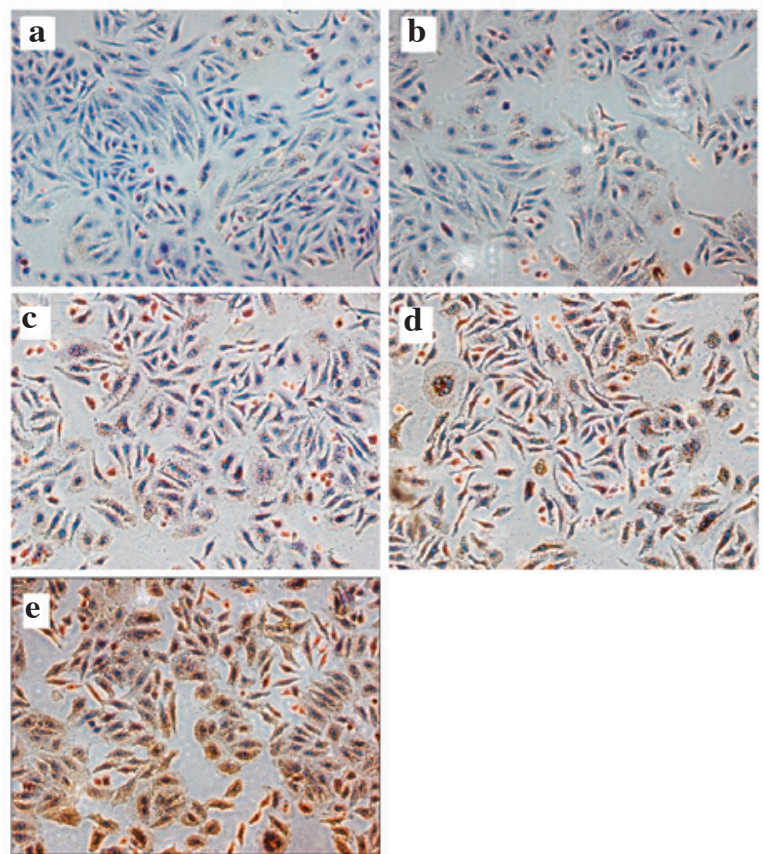

B
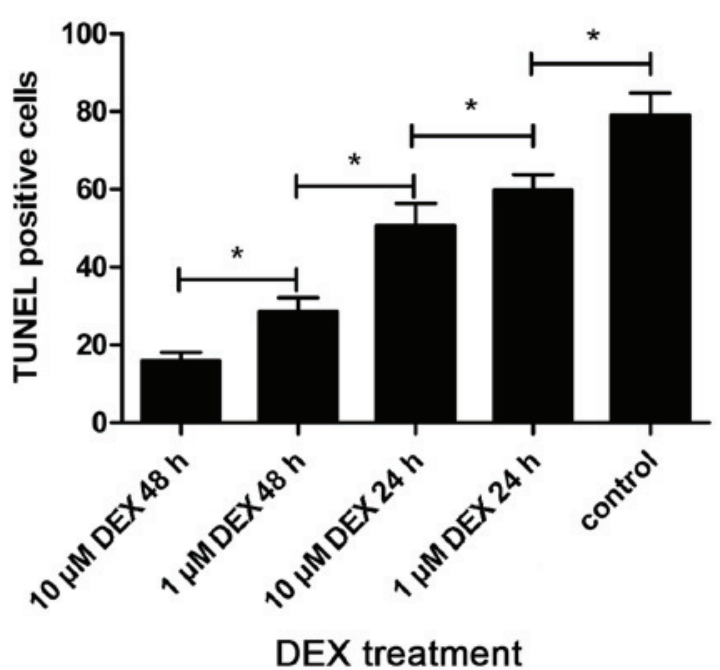

Figure 5. DEX protects L-02 cells from TRAIL-induced apoptosis. Apoptosis was evaluated using a TUNEL assay, and the number of apoptotic cells in each group was counted. (A) Representative photomicrographs of TUNEL-positive cells. L-02 cells were pretreated for $48 \mathrm{~h}$ with (a) $10 \mu \mathrm{M}$ or (b) $1 \mu \mathrm{M} \mathrm{DEX}$, and for $24 \mathrm{~h}$ with (c) $10 \mu \mathrm{M}$ or (d) $1 \mu \mathrm{M}$ DEX. (e) Control group of untreated L-02 cells. All the cells were treated with TRAIL for the induction of apoptosis. Magnification, x200. (B) Quantitative analysis of the levels of apoptosis. Data are presented as the mean \pm standard deviation. *P $<0.05$. DEX, dexamethasone; TRAIL, tumor necrosis factor-related apoptosis-inducing ligand; TUNEL, terminal deoxynucleotidyl transferase dUTP nick end labeling.

A

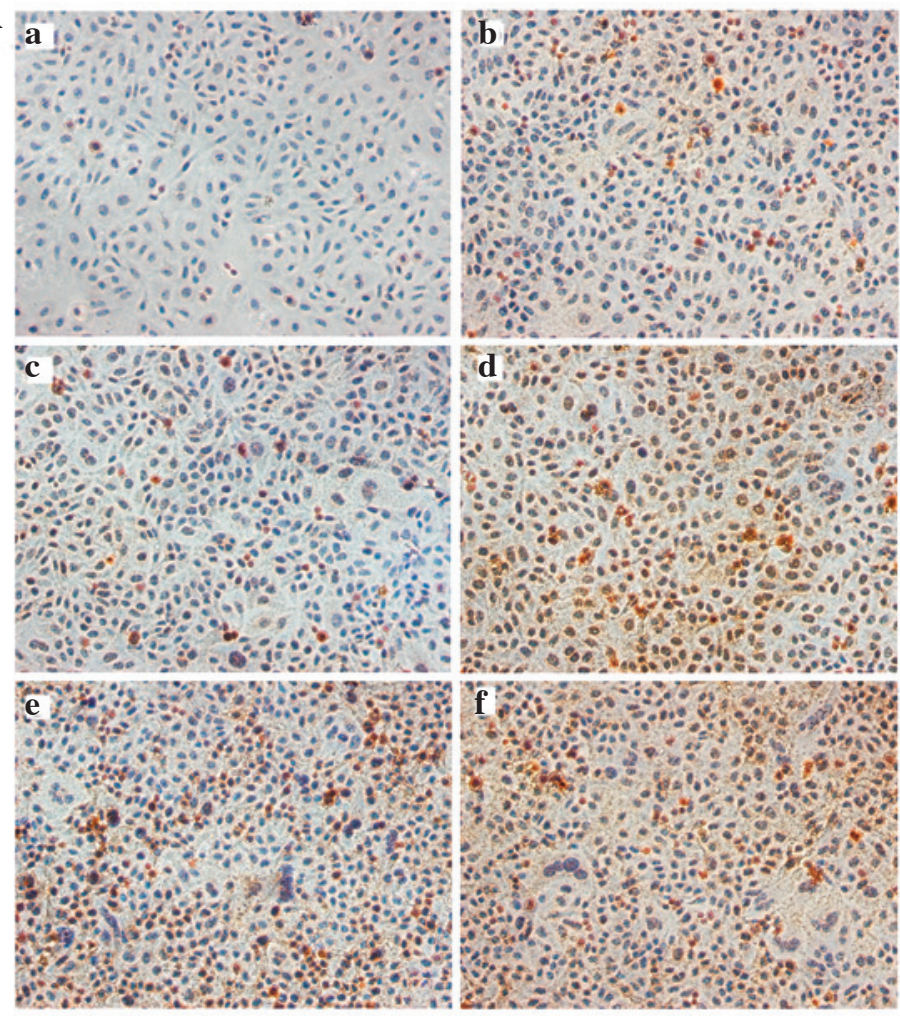

B

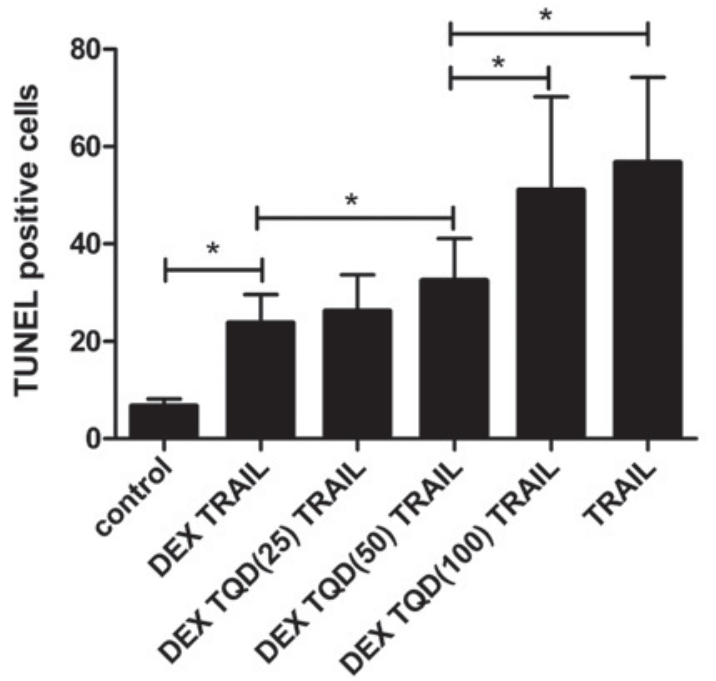

Figure 6. DEX protects L-02 cells from TRAIL-induced apoptosis by upregulating P-gp. Apoptosis was evaluated using a TUNEL assay, and the number of TUNEL-positive cells in each group were counted. (A) Representative photomicrographs of the TUNEL assay. L-02 cells were divided into six groups based on their treatment regimens, (a) control untreated group, (b) pretreated with $10 \mu \mathrm{M} \mathrm{DEX}$ for $24 \mathrm{~h}$, followed by incubation with TRAIL for $24 \mathrm{~h}$, (c) pretreatment with $10 \mu \mathrm{M}$ DEX for $24 \mathrm{~h}$, followed by incubation with TRAIL and $25 \mathrm{nM}$ TQD for $24 \mathrm{~h}$, (d) pretreated with $10 \mu \mathrm{M}$ DEX for $24 \mathrm{~h}$, followed by incubation with TRAIL and $50 \mathrm{nM}$ TQD for $24 \mathrm{~h}$, (e) pretreated with $10 \mu \mathrm{M}$ DEX for $24 \mathrm{~h}$, followed by incubation with TRAIL and $100 \mathrm{nM}$ TQD for $24 \mathrm{~h}$, and (f) incubated with TRAIL for $24 \mathrm{~h}$. All the groups were treated with TRAIL for the induction of apoptosis, with the exception of the control group. Magnification, x200. (B) Quantitative analysis of the levels of apoptosis. Data are presented as the mean \pm standard deviation. "P<0.05. DEX, dexamethasone; TRAIL, tumor necrosis factor-related apoptosis-inducing ligand; TQD, tariquidar; TUNEL, terminal deoxynucleotidyl transferase dUTP nick end labeling. 
with DEX and TRAIL $(\mathrm{P}<0.05)$. No significant difference was observed between the TRAIL-treated and TQD-treated (100 nM) groups.

\section{Discussion}

Studies have reported that DEX can induce the expression and function of P-gp in the blood-brain barrier, placenta and other tissues $(18,19)$. Therefore, the present study examined whether DEX increases the levels of P-gps in normal human liver cells. The results of the immunocytochemical and flow cytometric analyses revealed that pretreatment of L- 02 cells with DEX for 24-72 h significantly upregulated the levels of P-gps (Figs. 1B and $2 \mathrm{~B}$ ). The results of the western blot analysis demonstrated that pretreatment of the cells with DEX increased the expression P-gp in a time- and dose-dependent manner (Fig. 3). In addition, DEX also enhanced the mRNA levels of the ABCB1 gene, similar to the results obtained for the protein levels. These results suggested that pretreatment with DEX induced the expression of P-gp at the mRNA and protein levels in the L-02 cell line.

The results from previous studies reporting the effects of glucocorticoids on the expression of P-gps are inconsistent. In several studies, glucocorticoids, including DEX have been reported to upregulate the expression of P-gps, in agreement with the results of the present study. Salje et al reported the ability of DEX to upregulate the expression of P-gps in the liver (25), and the expression of P-gp also increased in the blood-brain barriers of DEX-treated animals in a report by Chan et al (19). These results are consistent with those reported by Petropoulos et al, which demonstrated the induction of placental P-gp, mediated by DEX (26). By contrast, other studies have demonstrated either no change or decreased expression levels of P-gps upon treatment of cells or animals with DEX. For example, Nishimura et al reported that DEX had a tendency to decrease the mRNA levels of the ABCB1 gene in monkey hepatocytes (27). Mark et al demonstrated that pre-treatment with glucocorticoids decreases the expression levels of P-gp in the placenta (28). Of note, DEX exerts varied effects on P-gps in different tissues and cell types. Previous studies have demonstrated that DEX pretreatment increases the levels of P-gp in the intestine, but not in the liver (29). Another study reported that DEX rapidly increases the expression levels of P-gps in the liver and lungs, but decreases their expression in kidneys (30). Glucocorticoid treatment exerts differing effects, even in the case of cell lines derived from the same tissue; the expression of P-gp is induced in LS180 cells, but downregulated in Caco-2 cells upon treatment (31). There is no definitive explanation for these contrasting results; however, it is possible that it is due to tissue specificity, as well as the complex regulation of this efflux transporter by glucocorticoids in certain organs.

Notably, incubation with DEX in the present study led to the transcriptional levels of the ABCB1 gene mRNA increasing in parallel with that of $\mathrm{P}-\mathrm{gp}$ protein levels. This correlation between the ABCB1 gene mRNA and the P-gp protein has been reported in previous studies, which are in good agreement with our studies. Narang et al demonstrated that DEX increases the expression of $\mathrm{P}$-gp in primary rat brain microvascular endothelial cells, and an increase in the mRNA expression of the ABCB1 gene results in a change in the protein expression of P-gp (18).
According to Salje et al, the mRNA and protein levels of P-gp are significantly induced by DEX in the fetal brain and liver (25). However, there are results contradicting those described above. Katayama et al demonstrated that the expression of P-gp can be increased without affecting its mRNA levels (32). Similarly, Micuda et al demonstrated that pretreatment with DEX results in an increase in the protein expression of P-gp, but a decrease in the mRNA expression of the ABCB1 gene in the liver (33). The present study hypothesized that the these differences may be due to the complex transcriptional regulation of MDR1, which involves several signaling pathways (34).

Several studies have provided evidence suggesting that DEX can protect several cells from apoptosis induced by drugs. Nieuwenhuis et al reported that DEX protects human fibroblasts from apoptosis (9). According to a study by Haake et al, DEX treatment also protects hair cells against apoptosis (10). Similarly, other studies have demonstrated that P-gps can exert anti-apoptotic effects. Ruefli et al reported that P-gps can specifically inhibit Fas-induced caspase activation and apoptosis (15), whereas Tainton et al demonstrated that P-gps inhibit apoptotic stimuli in lymphoma cells (16). In acute myeloid leukemia, resistance to apoptosis is associated with the expression of P-gp, as reported by Pallis et al (17). In view of these observations, the present study investigated whether DEX had similar anti-apoptotic effects on L-02 cells. The results revealed that pretreatment with DEX for 24-48 h effectively protected the L-02 cells from TRAIL-induced apoptotic cell death. A gradual increase in the protective effect was observed when the duration of treatment was increased between 24 and $48 \mathrm{~h}$, and when the concentration of DEX was increased between 1 and $10 \mu \mathrm{M}$. Together, these findings indicated that DEX pretreatment suppressed TRAIL-induced apoptosis in the L-02 cell line.

Previous studies have demonstrated that, in addition to their role in MDR, P-gps may also protect cells at two levels, by decreasing the accumulation of toxins in the cells and by inhibiting the apoptotic pathways induced by toxins and other stressors. Ruefli et al reported that P-gp can specifically inhibit caspase- 8 activation and apoptosis (15). Similarly, Pallis et al demonstrated that the expression and activity of $\mathrm{P}-\mathrm{gps}$ are associated with resistance to apoptosis in acute myeloid leukemia cells (17).

Therefore, the present study subsequently examined the anti-apoptotic effects of DEX on the cells, in which the functions of P-gps were inhibited by treatment with TQD, a P-gp inhibitor. The results revealed that, in addition to inducing the expression of P-gp, DEX alleviated cell apoptosis at increased concentrations and incubation periods. By contrast, treatment with TQD aggravated apoptosis in the L-02 cells, compared with the untreated cells. Additionally, the numbers of apoptotic cells were elevated with increasing concentrations of TQD. Based on these results, it is possible that DEX exerted anti-apoptotic and cell-protective effects through the induction of P-gps in the L-02 cell line.

In conclusion, the present study provided evidence that P-gps exist in L-02 cells, a normal human liver cell line, and the effect of DEX on the expression of P-gps in this cell line were investigated. It was demonstrated that pretreatment with DEX suppressed TRAIL-induced apoptosis in the L-02 cells. In addition, the results indicated that the induction of P-gp is 
likely a molecular mechanism underlying the anti-apoptotic effects of DEX. The results also suggest that the L-02 cell line is a suitable cell model for investigating the effects of glucocorticoids on transport proteins, including P-gp. In addition, this model may also assist in understanding the benefits of DEX for the treatment of hepatic failure and other liver diseases. Additional investigations are required for understanding the underlying molecular mechanisms by which DEX regulates the expression of P-gp in the L-02 cell line.

\section{Acknowledgements}

This study was supported by a grant from the Chinese National Natural Science Foundation project (grant. no. 81270525).

\section{References}

1. Levy P, Marcellin P, Martinot-Peignoux M, Degott C, Nataf J and Benhamou JP: Clinical course of spontaneous reactivation of hepatitis B virus infection in patients with chronic hepatitis B. Hepatology 12: 570-574, 1990.

2. Sarin SK, Kumar A, Almeida JA, Chawla YK, Fan ST, Garg H, de Silva HJ, Hamid SS, Jalan R, Komolmit P, et al: Acute-on-chronic liver failure: Consensus recommendations of the Asian Pacific Association for the study of the liver (APASL). Hepatol Int 3: 269-282, 2009.

3. Zhang XQ, Jiang L, You JP, Liu YY, Peng J, Zhang HY, Xu BY and Mao Q: Efficacy of short-term dexamethasone therapy in acute-on-chronic pre-liver failure. Hepatol Res 41: 46-53, 2011.

4. Fujiwara K, Yasui S, Yonemitsu Y, Fukai K, Arai M, Imazeki F, Suzuki A, Suzuki H, Sadahiro T, Oda S and Yokosuka O: Efficacy of combination therapy of antiviral and immunosuppressive drugs for the treatment of severe acute exacerbation of chronic hepatitis B. J Gastroenterol 43: 711-719, 2008.

5. Naveau S, Balian A, Capron F, Raynard B, Fallik D, Agostini H, Grangeot-Keros L, Portier A, Galanaud P, Chaput JC and Emilie D: Balance between pro and anti-inflammatory cytokines in patients with acute alcoholic hepatitis. Gastroenterol Clin Biol 29: 269-274, 2005.

6. Wang M, Shen F, Shi LH, Xi T, Li XF, Chen X and Wu MC: Protective effect of prednisolone on ischemia-induced liver injury in rats. World J Gastroenterol 14: 4332-4337, 2008.

7. Thoresen GH, Gjone IH, Gladhaug IP, Refsnes M, Ostby E and Christoffersen T: Studies of glucocorticoid enhancement of the capacity of hepatocytes to accumulate cyclic AMP. Pharmacol Toxicol 65: 175-180, 1989.

8. Jaeschke H, Gujral JS and Bajt ML: Apoptosis and necrosis in liver disease. Liver Int 24: 85-89, 2004.

9. Nieuwenhuis B, Lüth A and Kleuser B: Dexamethasone protects human fibroblasts from apoptosis via an S1P3-receptor subtype dependent activation of PKB/Akt and Bcl XL. Pharmacol Res 61: 449-459, 2010.

10. Haake SM, Dinh CT, Chen S, Eshraghi AA and Van De Water TR: Dexamethasone protects auditory hair cells against TNFalpha-initiated apoptosis via activation of PI3K/Akt and NFkappaB signaling. Hear Res 255: 22-32, 2009.

11. Li M, Chen F, Liu CP, Li DM, Li X, Wang C and Li JC: Dexamethasone enhances trichosanthin-induced apoptosis in the HepG2 hepatoma cell line. Life Sci 86: 10-16, 2010.

12. Gottesman MM and Pastan I: Biochemistry of multidrug resistance mediated by the multidrug transporter. Annu Rev Biochem 62: 385-427, 1993.

13. Ambudkar SV, Dey S, Hrycyna CA, Ramachandra M, Pastan I and Gottesman MM: Biochemical, cellular and pharmacological aspects of the multidrug transporter. Annu Rev Pharmacol Toxicol 39: 361-398, 1999.

14. Ruefli AA and Johnstone RW: A role for P-glycoprotein in regulating cell growth and survival. Clin Appl Immunol Rev 4: 31-47, 2003.

15. Ruefli AA, Tainton KM, Darcy PK, Smyth MJ and Johnstone RW: P-glycoprotein inhibits caspase-8 activation but not formation of the death inducing signal complex (disc) following fas ligation. Cell Death Differ 9: 1266-1272, 2002.
16. Tainton KM, Smyth MJ, Jackson JT, Tanner JE, Cerruti L, Jane SM, Darcy PK and Johnstone RW: Mutational analysis of P-glycoprotein: Suppression of caspase activation in the absence of ATP-dependent drug efflux. Cell Death Differ 11: 1028-1037, 2004.

17. Pallis M, Turzanski J, Grundy M, Seedhouse C and Russell N: Resistance to spontaneous apoptosis in acute myeloid leukaemia blasts is associated with p-glycoprotein expression and function, but not with the presence of FLT3 internal tandem duplications. Br J Haematol 120: 1009-1016, 2003.

18. Narang VS, Fraga C, Kumar N, Shen J, Throm S, Stewart CF and Waters CM: Dexamethasone increases expression and activity of multidrug resistance transporters at the rat blood-brain barrier. Am J Physiol Cell Physiol 295: C440-C450, 2008.

19. Chan GN, Saldivia V, Yang Y, Pang H, de Lannoy I and Bendayan R: In vivo induction of P-glycoprotein expression at the mouse blood-brain barrier: An intracerebral microdialysis study. J Neurochem 127: 342-352, 2013.

20. Rigalli JP, Perdomo VG, Luquita MG, Villanueva SS, Arias A, Theile D, Weiss J, Mottino AD, Ruiz ML and Catania VA: Regulation of biotransformation systems and ABC transporters by benznidazole in HepG2 cells: Involvement of pregnane X-receptor. PLoS Negl Trop Dis 6: e1951, 2012.

21. Jigorel E, Le Vee M, Boursier-Neyret C, Parmentier Y and Fardel O: Differential regulation of sinusoidal and canalicular hepatic drug transporter expression by xenobiotics activating drug-sensing receptors in primary human hepatocytes. Drug Metab Dispos 34: 1756-1763, 2006.

22. Livak KJ and Schmittgen TD: Analysis of relative gene expression data using real-time quantitative PCR and the 2(-Delta Delta C(T)) Method. Methods 25: 402-408, 2001.

23. Takeba Y, Sekine S, Kumai T, Matsumoto N, Nakaya S, Tsuzuki Y, Yanagida Y, Nakano H, Asakura T, Ohtsubo T and Kobayashi S: Irinotecan-induced apoptosis is inhibited by increasedP-glycoprotein expression and decreased p53 in human hepatocellular carcinoma cells. Biol Pharm Bull 30: 1400-1406, 2007.

24. Sakaeda T, Nakamura T, Hirai M, Kimura T, Wada A, Yagami T, Kobayashi H, Nagata S, Okamura N and Yoshikawa T: MDR1 up-regulated by apoptotic stimuli suppresses apoptotic signaling. Pharm Res 19: 1323-1329, 2002.

25. Salje K, Lederer K, Oswald S, DazertE, Warzok R and Siegmund W: Effects of rifampicin, dexamethasone, St. John's Wort and thyroxine on maternal and foetal expression of Abcbl and organ distribution of talinolol in pregnant rats. Basic Clin Pharmacol Toxicol 111: 99-105, 2012.

26. Petropoulos S, Gibb W and Matthews SG: Effect of glucocorticoids on regulation of placental multidrug resistance phosphoglycoprotein (P-gp) in the mouse. Placenta 31: 803-810, 2010.

27. Nishimura M, Koeda A, Morikawa H, Satoh T, Narimatsu S and Naito S: Comparison of inducibility of multidrug resistance (MDR)1, multidrug resistance-associated protein (MRP)1 and MRP2 mRNAs by prototypical microsomal enzyme inducers in primary cultures of human and cynomolgus monkey hepatocytes. Biol Pharm Bull 31: 2068-2072, 2008.

28. Mark PJ, Augustus S, Lewis JL, Hewitt DP and Waddell BJ: Changes in the placental glucocorticoid barrier during rat pregnancy: Impact on placental corticosterone levels and regulation by progesterone. Biol Reprod 80: 1209-1215, 2009.

29. Yumoto R, Murakami T, Sanemasa M, Nasu R, Nagai J and Takano M: Pharmacokinetic interaction of cytochrome P450 3A-related compounds with rhodamine 123, a P-glycoprotein substrate, in rats pretreated with dexamethasone. Drug Metab Dispos 29: 145-151, 2001.

30. Demeule M, Jodoin J, Beaulieu E, Brossard M and Béliveau R: Dexamethasone modulation of multidrug transporters in normal tissues. FEBS Lett 442: 208-214, 1999.

31. Maier A, Zimmermann C, Beglinger C, Drewe J and Gutmann H: Effects of budesonide on P-glycoprotein expression in intestinal cell lines. Br J Pharmacol 150: 361-368, 2007.

32. Katayama K, Noguchi K and Sugimoto Y: FBXO15 regulates P-glycoprotein/ABCB1 expression through the ubiquitin-proteasome pathway in cancer cells. Cancer Sci 104: 694-702, 2013.

33. Micuda S, Fuksa L, Mundlova L, Osterreicher J, Mokry J, Cermanova J, Brcakova E, Staud F, Pokorna P and Martinkova J: Morphological and functional changes in p-glycoprotein during dexamethasone-induced hepatomegaly. Clin Exp Pharmacol Physiol 34: 296-303, 2007.

34. Mizutani T and Hattori A: New horizon of MDR1 (P-glycoprotein) study. Drug Metab Rev 37: 489-510, 2005. 